\title{
A Redox-Innocent Uranium(IV)-Quinoid Metal-Organic Framework
}

Refn, Vanja E.; Kubus, Mariusz; Mossin, Susanne; Larsen, Rene Wugt; Pedersen, Kasper Steen

Published in:

ACS Omega

Link to article, DOI:

10.1021/acsomega.9b03727

Publication date:

2020

Document Version

Publisher's PDF, also known as Version of record

Link back to DTU Orbit

Citation (APA):

Refn, V. E., Kubus, M., Mossin, S., Larsen, R. W., \& Pedersen, K. S. (2020). A Redox-Innocent Uranium(IV)Quinoid Metal-Organic Framework. ACS Omega, 5(7), 3462-3466. https://doi.org/10.1021/acsomega.9b03727

\section{General rights}

Copyright and moral rights for the publications made accessible in the public portal are retained by the authors and/or other copyright owners and it is a condition of accessing publications that users recognise and abide by the legal requirements associated with these rights.

- Users may download and print one copy of any publication from the public portal for the purpose of private study or research.

- You may not further distribute the material or use it for any profit-making activity or commercial gain

- You may freely distribute the URL identifying the publication in the public portal

If you believe that this document breaches copyright please contact us providing details, and we will remove access to the work immediately and investigate your claim. 


\title{
A Redox-Innocent Uranium(IV)-Quinoid Metal-Organic Framework
}

\author{
Vanja E. Refn, Mariusz Kubus, Susanne Mossin, René Wugt Larsen, and Kasper S. Pedersen* \\ Cite This: ACS Omega 2020, 5, 3462-3466 \\ Read Online
}

\section{ACCESS | Lill Metrics \& More | 回 Article Recommendations ｜（） Supporting Information}

ABSTRACT: Quinoid-based ligands constitute the most common class of redox-active ligands used to construct electrically conductive and magnetic metal-organic frameworks (MOFs). Whereas this chemistry is intensively explored for transition-metal and lanthanide ions, any related actinide compound has not received attention. In particular, the MOF chemistry of actinide ions in the lower oxidation states is underexplored. We herein report the synthesis, and structural and physical property characterization of a uranium(IV) quinoid-based MOF, $\left[\mathrm{U}\left(\mathrm{Cl}_{2} \mathrm{dhbq}\right)_{2}\left(\mathrm{H}_{2} \mathrm{O}\right)_{2}\right] \cdot 4 \mathrm{H}_{2} \mathrm{O}\left(1, \mathrm{Cl}_{2} \mathrm{dhbq}^{2-}=\right.$ deprotonated 2,5-dichloro-3,6-dihydroxybenzoquinone). 1 is a rare example of a $U(I V)$-based coordination solid and the first material to incorporate bona fide reducible bridging ligands. Despite the anticipated thermodynamic

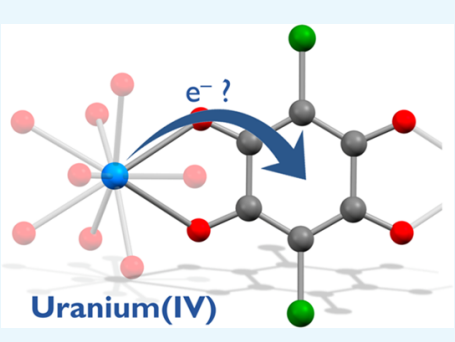
driving force, no indications of valence tautomerism are evident from magnetometry, near-IR spectroscopy, and X-band electron paramagnetic resonance measurements. These initial results suggest that reduction potentials alone are insufficient as guidelines for the prediction of the occurrence of electron transfer in uranium-quinoid-based materials.

\section{INTRODUCTION}

Metal-organic frameworks (MOFs), and coordination solids in general, receive ever-increasing attention and numerous examples of transition-metal-based MOFs have been reported to exhibit interesting properties relevant for gas separation and storage, and catalysis. ${ }^{1-3}$ Recent studies have highlighted the possibilities to design MOFs with high electrical conductivity applicable in supercapacitors and chemical sensors, owing to the significant orbital overlap between the metal ions and the bridging ligands. ${ }^{4-6}$ On the contrary, the f-element-based MOFs are not as widely explored, ${ }^{7}$ and actinide-based MOFs are relatively rare. ${ }^{8-11}$ Whereas the majority of the existing uranium MOFs encompass $\mathrm{UO}_{2}{ }^{2+}$ units, ${ }^{8,12}$ the reducing nature of the lower oxidation states $\mathrm{U}(\mathrm{IV})$ and $\mathrm{U}(\mathrm{III})$ make these metal ion units interesting components for MOFs comprising redox-active ligand scaffolds. Notably, the few, previously reported uranium(IV) MOFs are all based on redox-inactive carboxylate ligands. ${ }^{13-17}$ The introduction of $\mathrm{U}(\mathrm{IV})-\mathrm{L} \leftrightarrow \mathrm{U}(\mathrm{V})-\mathrm{L}^{\bullet}$ valence tautomerism in MOFs would parallel the current methodology employed in transition-metal chemistry to reveal strong magnetic interaction and electronic conductivity through ligand-based mixed-valency. ${ }^{18}$ Despite the growing interest in uranium coordination chemistry of redox-active ligands, ${ }^{19,20}$ no noninnocent systems have been reported to extend beyond the dimensionality of an isolated molecule. In transition-metal-based coordination solids, an often-used redox-active ligand is 2,5-dichloro-3,6-dihydroxybenzoquinone ("chloranilic acid"; $\mathrm{Cl}_{2} \mathrm{dhbqH}_{2}$ ), which may be reduced by up to two electrons, owing to the energetically lowlying $\pi^{*}$ orbitals (Figure 1). ${ }^{21,22}$

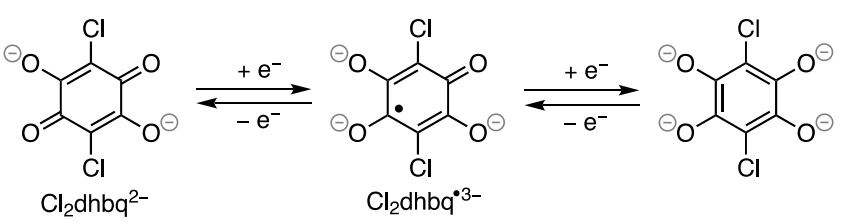

Figure 1. Schematic overview of the accessible redox states of $\mathrm{Cl}_{2} \mathrm{dhbq}^{n-}$.

Several examples of iron-based dihydroxybenzoquinone coordination solids have been shown to display strong magnetic interactions and high electrical conductivity attributed to mixed-valency in the dihydroxybenzoquinone ligand scaffold. ${ }^{23-27}$ Whereas many lanthanide systems incorporating closed-shell dihydroxybenzoquinone ligands have been reported, ${ }^{28}$ the only few examples of actinide ion systems incorporate nonoxidizable $\mathrm{Th}(\mathrm{IV})$ and $\mathrm{U}(\mathrm{VI}) .^{28-31} \mathrm{In}$ aqueous solution, $\mathrm{U}(\mathrm{IV})$ is moderately reducing and comparable in reduction potential to the $\mathrm{Fe}$ (III) $/ \mathrm{Fe}$ (II) redox-couple. $^{32}$ It could thus be hypothesized that $\mathrm{U}(\mathrm{IV})$ should be capable of reducing $\mathrm{Cl}_{2} \mathrm{dhbq}^{2-}$ to the monoradical $\mathrm{Cl}_{2} \mathrm{dhbq}^{3-}$, thereby creating a pathway for strong $2 \mathrm{p}-5 \mathrm{f}$ magnetic superexchange interactions and facilitating hopping conduction between $\mathrm{Cl}_{2} \mathrm{dhbq}^{2-/ \bullet 3-}$ units. Following this hypothesis we, herein, report on a unique example of a uranium(IV) coordination solid constructed using quinoidbased bridging struts.

Received: November 4, 2019

Accepted: January 14, 2020

Published: February 10, 2020 

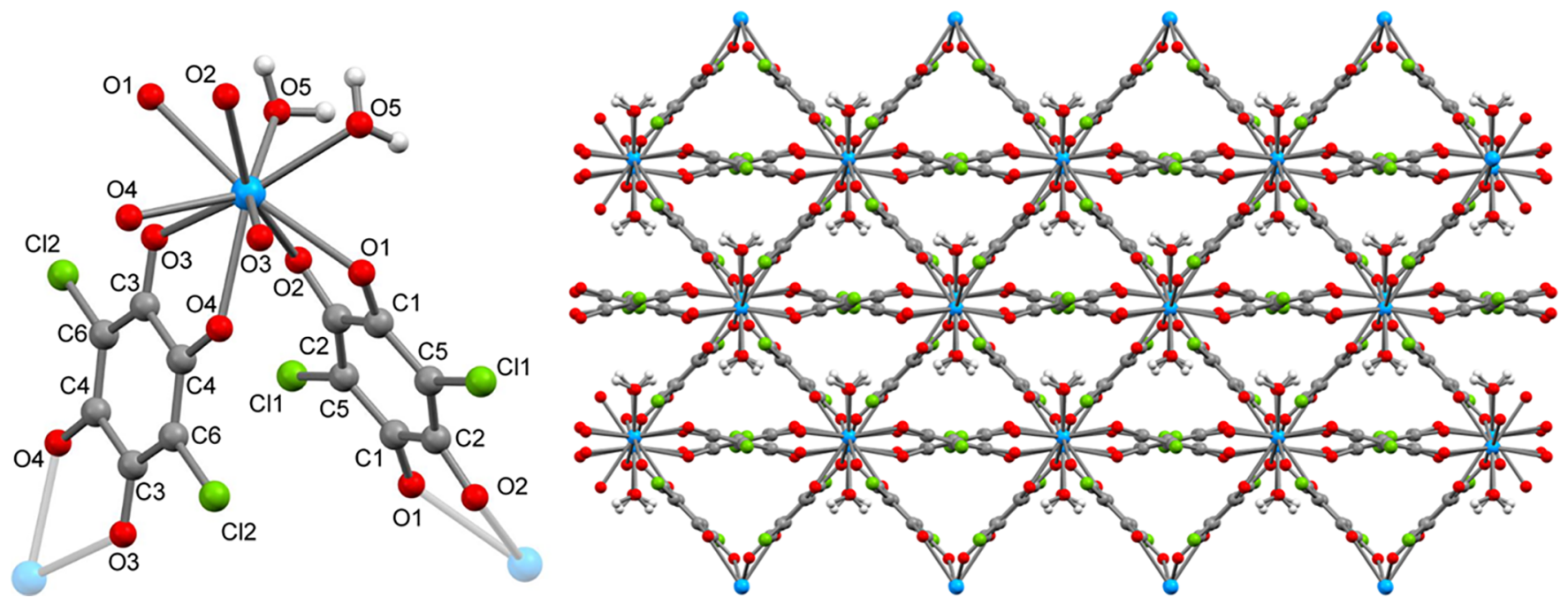

Figure 2. Left: Local coordination environment of the uranium center in $1(T=120 \mathrm{~K})$. Cocrystallized water molecules are omitted for clarity. Selected bond lengths ( $)$ : U-O1 2.502(2), U-O2 2.477(2), U-O3 2.401(2), U-O4 2.476(2), C1-O1 1.258(3), C2-O2 1.267(4), C1-C2 $1.522(4), \mathrm{C} 3-\mathrm{O} 31.265(3), \mathrm{C} 4-\mathrm{O} 41.258(3), \mathrm{C} 3-\mathrm{C} 41.531(4)$. Right: View of the extended coordination polymer structure shown along the triangular pores corresponding to viewed perpendicular to the crystallographic $[1,0,-1]$ plane. Pore-filling cocrystallized water molecules have been omitted for clarity. Color code: $\mathrm{U}$, blue; $\mathrm{Cl}$, green; $\mathrm{O}$, red; $\mathrm{C}$, gray; $\mathrm{H}$, white.

\section{RESULTS AND DISCUSSION}

The slow diffusion of an aqueous solution of $\mathrm{Cl}_{2} \mathrm{dhbqH}_{2}$ into an aqueous suspension of uranium(IV) sulfate tetrahydrate
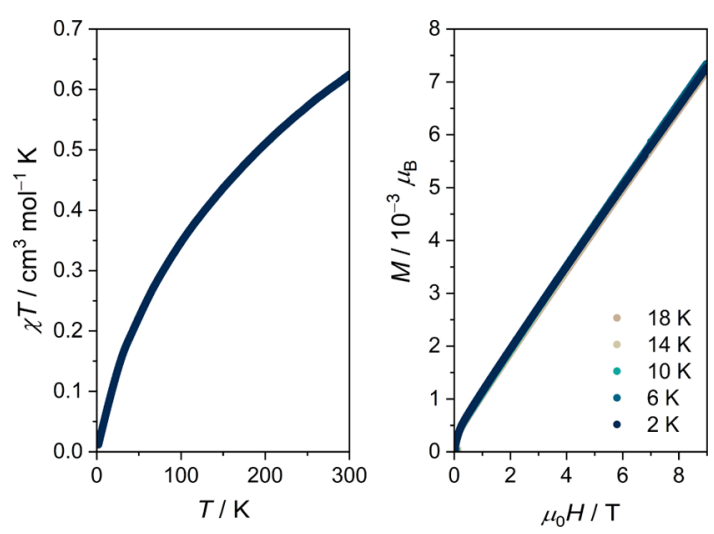

Figure 3. Left: Temperature dependence of the $\chi T\left(\chi \equiv M / \mu_{0} H\right)$ product of a polycrystalline specimen of $\mathbf{1}$ obtained in a magnetic field of $\mu_{0} H=1$ T. Right: Magnetic field dependence of the magnetization at selected low temperatures.

yielded a black, crystalline material after several weeks. Singlecrystal X-ray diffraction analysis revealed the solid to be a three-dimensional polymeric structure, isostructural to the $\mathrm{Th}(\mathrm{IV})$ analogue reported by Robson and co-workers, ${ }^{28}$ with the stoichiometry of $\left[\mathrm{U}\left(\mathrm{Cl}_{2} \mathrm{dhbq}\right)_{2}\left(\mathrm{H}_{2} \mathrm{O}\right)_{2}\right] \cdot 4 \mathrm{H}_{2} \mathrm{O}(\mathbf{1})$. X-ray powder diffractometry (see Figure $\mathrm{S} 1$ ) and elemental analysis confirm the homogeneity of the material and the absence of any traces of unreacted starting materials. The local coordination environment around the crystallographically unique uranium center is shown in Figure 2 (left) and selected structural metrics are provided in the figure caption. The structure comprises a ten-coordinate uranium center bridged to adjacent uranium centers through four $\mathrm{Cl}_{2} \mathrm{dhbq}^{n-}$ ligands, which coordinate to each uranium center in a bidentate fashion (Figure 2). The coordination sphere is completed by two water molecules which are hydrogen-bonded to cocrystallized water molecules (Figure S2). The $\mathrm{C} 2 / c$ crystallographic space group generates triangular pores perpendicular to the $[1,0,-1]$ crystallographic plane as depicted in Figure 2 (right). Heating of polycrystalline 1 initially leads to loss of six water molecules as determined by thermogravimetric analysis (Figure S3) and a concurrent loss of crystallinity. Likewise, $\mathrm{N}_{2}$-sorption measurements of polycrystalline 1 activated in vacuo at $80{ }^{\circ} \mathrm{C}$ reveal no permanent porosity. The structure features two crystallographically distinct $\mathrm{Cl}_{2} \mathrm{dhbq}^{n-}$ ligands, as shown in Figure 2

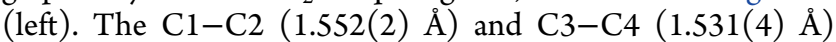
bond lengths are in the normal range for $\mathrm{Cl}_{2} \mathrm{dhbq}^{2-}$ and significantly longer than the values previously found for $\mathrm{Cl}_{2} \mathrm{dhbq}^{\bullet-}$ (e.g,. 1.456(3) $\AA$ in $\left[(\mathrm{TPyA}) \mathrm{Co}^{\mathrm{III}}\left(\mathrm{Cl}_{2} \mathrm{dhbq}^{\bullet-}\right)\right.$ $\left.\mathrm{Co}^{\mathrm{III}}(\mathrm{TPyA})\right]^{3+} ;$ TPyA $=$ tris (2-pyridylmethyl)-amine $) .{ }^{33}$ Similarly, the $\mathrm{C}-\mathrm{O}$ bonds are all in the range of 1.258(3) to 1.267(4) $\AA$, which are far from the 1.312(2) $\AA$ found in $\left[(\mathrm{TPyA}) \mathrm{Co}^{\mathrm{III}}\left(\mathrm{Cl}_{2} \mathrm{dhbq}^{\bullet-}\right) \mathrm{Co}^{\mathrm{III}}(\mathrm{TPyA})\right]^{3+}$. Further comparison to the bond lengths of the Th(IV) analogue reveals only little differences with an average $\mathrm{Th}-\mathrm{O}$ bond length of $2.50 \AA$ versus $2.47 \AA$ in 1 , and an average $\mathrm{O}-\mathrm{C}$ bond length in the compound of $1.26 \AA$ versus $1.26 \AA$ in $1 .^{28}$ Analysis of a crystal at $T=285 \mathrm{~K}$ reveals only a small thermal expansion of the unit cell (coefficient of thermal expansion $=1.6 \times 10^{-4} \mathrm{~K}^{-1}$, Table $\mathrm{S} 1$ ) as compared to the $120 \mathrm{~K}$ data set. In conclusion, the structural analysis of 1 suggests the absence of any valence tautomerism and a formulation of $\mathbf{1}$ based on $\mathrm{U}(\mathrm{IV})$ and closed-shell $\mathrm{Cl}_{2} \mathrm{dhbq}^{2-}$. Mixed-valency systems commonly exhibit intense intervalence charge transfer (IVCT) transitions in the near-infrared energy regime. For $\mathrm{Cl}_{2} \mathrm{dhbq}^{n-}$-based coordination solids, these transitions are attributed to the interconversion of $\mathrm{Cl}_{2} \mathrm{dhbq}^{2-}$ and $\mathrm{Cl}_{2} \mathrm{dhbq}^{\bullet 3-} \cdot{ }^{23}$ The nearinfrared absorption spectra of $\mathbf{1}$ reveal the absence of any IVCT bands between 4000 and $10000 \mathrm{~cm}^{-1}$ (see Figure S4), suggesting an absence of any organic mixed-valency in $\mathbf{1}$. Likewise, the pressed pellet electrical resistance of 1 exceeds several megaohm at room temperature, reflecting its highly insulating nature. To corroborate the oxidation state assignment, the magnetic moment of $\mathbf{1}$ was measured as a function of temperature and magnetic field (Figures 3 and S5). The room 
temperature value of the magnetic susceptibility-temperature product $(\chi T)$ amounts to $0.62 \mathrm{~cm}^{3} \mathrm{~K} \mathrm{~mol}^{-1}$. This value is significantly lower than the one calculated for the RussellSaunders ${ }^{3} \mathrm{H}_{4}\left(5 \mathrm{f}^{2}, g_{\mathrm{J}}=4 / 5\right)$ term of $1.60 \mathrm{~cm}^{3} \mathrm{~K} \mathrm{~mol}^{-1}$. The magnetic moment of uranium-based complexes has been shown to be diagnostic of the oxidation state. ${ }^{34}$ However, the room temperature magnetic moments are broadly distributed around $0.96 \mathrm{~cm}^{3} \mathrm{~K} \mathrm{~mol}^{-1}$ and show overlap with the corresponding values for both $\mathrm{U}(\mathrm{III})$ and $\mathrm{U}(\mathrm{V})$. Upon descending temperature, the $\chi T$ product gradually decreases to withdraw $\left(\sim 6 \times 10^{-3} \mathrm{~cm}^{3} \mathrm{~K} \mathrm{~mol}^{-1}\right)$ at $2 \mathrm{~K}$. The vanishing $\chi T$ product suggests the presence of a nonmagnetic ground state, which is commonly encountered in U(IV), and is thus not expected to arise from antiferromagnetic U(IV)-U(IV) interactions. Recently, Arnold and co-workers reported the first examples of dinuclear U(IV) complexes bridged by quinoid ligands. ${ }^{35}$ Their experimental and theoretical investigations revealed a complete irrelevance of superexchange interactions across closed-shell quinoids bridging two U(IV) centers. The low-temperature magnetic field dependence of the magnetization of $\mathbf{1}$ is shown in Figure 3 (right panel). The approximately linear behavior of $M$ versus $\mu_{0} H$ is reminiscent of a nonmagnetic ground state with a significant contribution from temperature-independent paramagnetism. This conclusion is supported by X-band electron paramagnetic resonance spectroscopy where no resonances could be observed between room temperature and liquid $\mathrm{N}_{2}$-temperature, suggesting a complete absence of any $\mathrm{Cl}_{2} \mathrm{dhbq}^{\bullet-}$ radical species in $\mathbf{1}$ (Figure S6).

\section{CONCLUSIONS}

We have reported the synthesis and structural characterization of a rare example of a uranium-based MOF not built on uranyl(VI)-nodes. Analysis of the structural, spectroscopic, and magnetic data suggest the presence of uranium in oxidation state $+\mathrm{IV}$, despite the company of reducible $\mathrm{Cl}_{2} \mathrm{dhbq}^{2-}$ bridging ligands. It is tempting to speculate that, irrespective of the favorable redox potentials of U(IV), the absence of strong uranium-ligand covalency may impede the metalligand electron-transfer mechanism found in a plethora of $3 \mathrm{~d}$ transition metal ion analogues. These initial results may thus encourage further interest in the synthesis and characterization of actinide coordination solids based on redox-active ligands, with the ultimate goal of authenticating strong magnetic superexchange interactions and electronic conductivity.

\section{EXPERIMENTAL SECTION}

Materials and Instrumentation. Warning: Depleted uranium (primarily ${ }^{238} \mathrm{U}, t_{1 / 2}=4.5 \times 10^{9} \mathrm{y}$ ) is a weak $\alpha$ emitter and its chemical compounds are toxic. All manipulations were done in ventilated fume hoods at ambient conditions. $\mathrm{U}\left(\mathrm{SO}_{4}\right)_{2} \cdot x \mathrm{H}_{2} \mathrm{O}$ was synthesized following the procedure reported by Peres et al. ${ }^{36}$ The $x=4$ formulation was determined by powder X-ray diffraction analysis (see Figure S7). 2,5-Dichloro-3,5-dihydroxybenzoquinone was purchased from Sigma-Aldrich and used as received. Elemental analyses were performed on a Thermo Scientific FlashSmart CHNS/O Elemental Analyzer. The magnetization and electrical conductivity data were obtained on a QuantumDesign DynaCool Physical Property Measurement System equipped with a vibrating sample magnetometer and a $9 \mathrm{~T}$ dc magnet. The sample was immobilized in a standard
Table 1. Crystallographic and Refinement Parameters of 1 $(120 \mathrm{~K})$

\begin{tabular}{|c|c|}
\hline CCDC number & 1897474 \\
\hline empirical formula & $\mathrm{C}_{12} \mathrm{H}_{12} \mathrm{Cl}_{4} \mathrm{O}_{14} \mathrm{U}$ \\
\hline formula weight & 760.05 \\
\hline crystal system & monoclinic \\
\hline space group & $\mathrm{C} 2 / \mathrm{c}$ \\
\hline$a / \AA$ & $13.7293(4)$ \\
\hline$b / \AA$ & $11.3630(4)$ \\
\hline$c / \AA$ & $12.5175(4)$ \\
\hline$\alpha / \operatorname{deg}$ & 90 \\
\hline$\beta / \operatorname{deg}$ & $95.847(3)$ \\
\hline$\gamma / \operatorname{deg}$ & 90 \\
\hline$V / \AA^{3}$ & $1942.6(1)$ \\
\hline$Z$ & 4 \\
\hline$\rho_{\text {calc }} / \mathrm{g} \mathrm{cm}^{-3}$ & 2.599 \\
\hline$\mu / \mathrm{mm}^{-1}$ & 8.980 \\
\hline$F(000)$ & 1424.0 \\
\hline radiation & Mo $\mathrm{K} \alpha(\lambda=0.71073 \AA)$ \\
\hline $2 \theta$ range for data collection/deg & $5.52-58.988$ \\
\hline index ranges & $-13 \leq h \leq 18$ \\
\hline & $-14 \leq k \leq 13$ \\
\hline & $-17 \leq l \leq 17$ \\
\hline & $-14 \leq k \leq 13$ \\
\hline & $-17 \leq l \leq 17$ \\
\hline reflections collected & 9176 \\
\hline independent reflections & $2437\left[R_{\text {int }}=0.0282, R_{\text {sigma }}=0.0249\right]$ \\
\hline data/restrains/parameters & $2437 / 0 / 148$ \\
\hline goodness of fit on $F^{2}$ & 1.042 \\
\hline final $R$ indexes $[I \geq 2 \sigma(I)]$ & $R_{1}=0.0183, \mathrm{w} R_{2}=0.0435$ \\
\hline final $R$ indexes [all data] & $R_{1}=0.0201, w R_{2}=0.0442$ \\
\hline largest diff. peak/hole/e $\AA^{-3}$ & $1.53 /-0.66$ \\
\hline
\end{tabular}

QuantumDesign powder capsule attached to a brass sample holder. The magnetization was measured as a function of temperature $(1.8-300 \mathrm{~K})$ and field $(0-9 \mathrm{~T})$ and the data were corrected for diamagnetic contributions from the sample holder and the sample. The MIR and NIR attenuated-totalreflectance (ATR) spectra were collected by a Bruker VERTEX80v Fourier transform vacuum spectrometer employing a single-reflection diamond ATR accessory. The apparatus was configured with $\mathrm{KBr}(\mathrm{MIR}) / \mathrm{CaF}_{2}$ (NIR) beam splitters, liquid-nitrogen-cooled $\mathrm{HgCdTe}(\mathrm{MIR}) / \mathrm{InSb}$ (NIR) detectors, and globar (MIR)/tungsten (NIR) radiation sources. Extended ATR corrections were applied to account for the wavelengthdependent penetration depth of the probe beams. The complementary MIR Fourier transform Raman spectrum was collected by a Bruker RAM II module employing a $1000 \mathrm{~mW}$ near-infrared Nd:YAG excitation laser $(1064 \mathrm{~nm})$ and a liquidnitrogen-cooled Ge detector. A Mettler-Toledo thermogravimetric analyzer equipped with a built-in calibration weight was used to obtain data in the temperature range $25-465^{\circ} \mathrm{C}$ with a ramping speed of $0.5^{\circ} \mathrm{C} \mathrm{min}^{-1}$.

Synthesis. An aqueous solution of 2,5-dichloro-3,6dihydroxybenzoquinone $(16 \mathrm{mg}, 0.076 \mathrm{mmol}$ ) was carefully layered on top of an aqueous suspension $(6.5 \mathrm{~mL})$ of uranium(IV) sulfate tetrahydrate $(32 \mathrm{mg}, 0.064 \mathrm{mmol})$ in a borosilicate vial $(\varnothing 20 \mathrm{~mm})$. The vial was sealed and left undisturbed for 2 weeks at room temperature. The highly crystalline, black material was isolated by filtration. Yield: $\sim 50 \%$. Anal. Calcd (found) for $\mathrm{C}_{12} \mathrm{H}_{12} \mathrm{Cl}_{4} \mathrm{O}_{14} \mathrm{U}$ : C, $19.0 \%$ (18.9\%); H, $1.6 \%$ (1.81\%). Characteristic Raman shifts 
$\left(\mathrm{cm}^{-1}\right):$ 292, 389, 738, 1217, 1300, 1382 (cf. Figure S8). Characteristic IR frequencies $\left(\mathrm{cm}^{-1}\right): 444,571,609,855$, 1002, 1250, 1356, 1471 (cf. Figure S8).

X-ray Diffraction. Single crystals of 1 were selected and mounted on nylon loops on a SuperNova dual source CCDdiffractometer. The crystal was kept at $120 \mathrm{~K}$ during data collection. Using Olex $2,{ }^{37}$ the structure was solved by direct methods using the SIR $2004^{38}$ structure solution program and refined by Least Squares using version 2014/7 of ShelXL (Table 1). ${ }^{39}$ All nonhydrogen atoms were refined anisotropically. Hydrogen atom positions were calculated geometrically and refined using the riding model. The X-ray powder patterns were measured on a Huber G670 powder diffractometer using $\mathrm{Cu} \mathrm{K} \alpha_{1}(\lambda=1.5406 \AA$, quartz monochromator) radiation .

\section{ASSOCIATED CONTENT}

\section{(s) Supporting Information}

The Supporting Information is available free of charge at https://pubs.acs.org/doi/10.1021/acsomega.9b03727.

Additional experimental data (PDF)

Crystallographic data $(120 \mathrm{~K})(\mathrm{CIF})$

Crystallographic data (RT) (CIF)

\section{AUTHOR INFORMATION}

\section{Corresponding Author}

Kasper S. Pedersen - Department of Chemistry, Technical University of Denmark DK-2800 Kgs. Lyngby, Denmark; ○ orcid.org/0000-0002-4381-4544; Email: kastp@ kemi.dtu.dk

\section{Authors}

Vanja E. Refn - Department of Chemistry, Technical University of Denmark DK-2800 Kgs. Lyngby, Denmark

Mariusz Kubus - Department of Chemistry, Technical University of Denmark DK-2800 Kgs. Lyngby, Denmark; (1) orcid.org/0000-0002-1764-0376

Susanne Mossin - Department of Chemistry, Technical University of Denmark DK-2800 Kgs. Lyngby, Denmark; (1) orcid.org/0000-0001-7763-9660

René Wugt Larsen - Department of Chemistry, Technical University of Denmark DK-2800 Kgs. Lyngby, Denmark; (1) orcid.org/0000-0003-2983-6795

Complete contact information is available at: https://pubs.acs.org/10.1021/acsomega.9b03727

\section{Notes}

The authors declare no competing financial interest.

\section{ACKNOWLEDGMENTS}

K.S.P. thanks the VILLUM Foundation for a VILLUM Young Investigator grant (15374), and the Carlsberg Foundation (CF-17-0637), the Brdr. Hartmanns foundation, and the Torkil Holm foundation for research infrastructure grants. Dr. J. J. Mielby, L. Voigt, and B. F. Holten are thanked for experimental assistance.

\section{REFERENCES}

(1) Li, J.-R.; Sculley, J.; Zhou, H.-C. Metal-Organic Frameworks for Separations. Chem. Rev. 2012, 112, 869-932.

(2) Zhu, L.; Liu, X.-Q.; Jiang, H.-L.; Sun, L.-B. Metal-Organic Frameworks for Heterogeneous Basic Catalysis. Chem. Rev. 2017, 117, 8129-8176.
(3) Sun, L.; Campbell, M. G.; Dincă, M. Electrically Conductive Porous Metal-Organic Frameworks. Angew. Chem., Int. Ed. 2016, 55, $3566-3579$.

(4) Dou, J.-H.; Sun, L.; Ge, Y.; Li, W.; Hendon, C. H.; Li, J.; Gul, S.; Yano, J.; Stach, E. A.; Dincă, M. Signature of Metallic Behaviour in Metal-Organic Frameworks $\mathrm{M}_{3}$ (hexaiminobenzene $)_{2}(\mathrm{M}=\mathrm{Ni}, \mathrm{Cu})$. J. Am. Chem. Soc. 2017, 139, 13608-13611.

(5) Sheberla, D.; Bachman, J. C.; Elias, J. S.; Sun, C.-J.; Shao-Horn, Y.; Dincă, M. Conductive MOF electrodes for stable supercapacitors with high areal capacitance. Nat. Mater. 2017, 16, 220-224.

(6) Aubrey, M. L.; Kapelewski, M. T.; Melville, J. F.; Oktawiec, J.; Presti, D.; Gagliardi, L.; Long, J. R. Chemiresistive Detection of Gaseous Hydrocarbons and Interrogation of Charge Transport in $\mathrm{Cu}\left[\mathrm{Ni}(2,3-\text { pyrazinedithiolate })_{2}\right]$ by Gas Adsorption. J. Am. Chem. Soc. 2019, 141, 5005-5013.

(7) Bosch, M.; Chen, B.; Chen, J.; Chen, L.; Cheng, P.; Cimpoesu, F.; Ferbinteanu, M.; Fordham, S.; Hong, M.; Jiang, F.; Li, B.; Liu, K.; Liu, W.; Shi, W.; Song, S.-Y.; Song, X.-Z.; Su, J.; Tanase, S.; Tang, X.; Wang, X.; Wu, M.; Zhang, H.-J.; Zhang, Z.; Zheng, Z.; Zhou, H.-C.; Zhou, K. Lanthanide Metal-Organic Frameworks; Springer International Publishing Switzerland, 2015.

(8) Su, J.; Chen, J. Lanthanide Metal-Organic Frameworks; Cheng, P., Ed.; Springer International Publishing Switzerland, 2015; MOFs of Uranium and the Actinides, pp 265-296.

(9) Volkringer, C.; Mihalcea, I.; Vigier, J.-F.; Beaurain, A.; Visseaux, M.; Loiseau, T. Metal-Organic-Framework-Type 1D-Channel Open Network of a Tetravalent Uranium Trimesate. Inorg. Chem. 2011, 50, 11865-11867.

(10) Falaise, C.; Volkringer, C.; Loiseau, T. Mixed FormateDicarboxylate Coordination Polymers with Tetravalent Uranium: Occurrence of Tetranuclear $\left\{\mathrm{U}_{4} \mathrm{O}_{4}\right\}$ and Hexanuclear $\left\{\mathrm{U}_{6} \mathrm{O}_{4}(\mathrm{OH})_{4}\right\}$ Motifs. Cryst. Growth Des. 2013, 13, 3225-3231.

(11) Martin, N. P.; März, J.; Volkringer, C.; Henry, N.; Hennig, C.; Ikeda-Ohno, A.; Loiseau, T. Synthesis of Coordination Polymers of Tetravalent Actinides (Uranium and Neptunium) with Phthalate or Mellitate Ligand in Aqueous Medium. Inorg. Chem. 2017, 56, 29022913.

(12) Li, P.; Vermeulen, N. A.; Malliakas, C. D.; Gómez-Gualdrón, D. A.; Howarth, A. J.; Mehdi, B. L.; Dohnalkova, A.; Browning, N. D.; O'Keeffe, M.; Farha, O. K. Bottom-up construction of a superstructure in a porous uranium-organic crystal. Science 2017, 356, 624627

(13) Imaz, I.; Bravic, G.; Sutter, J.-P. Structural and zeolitic features of a series of heterometallic supramolecular porous architectures based on tetrahedral $\left\{\mathrm{M}\left(\mathrm{C}_{2} \mathrm{O}_{4}\right)_{4}\right\}^{4-}$ primary building units. Dalton Trans. 2005, 2681-2687.

(14) Imaz, I.; Bravic, G.; Sutter, J.-P. Structural and zeolitic features of a 3D heterometallic porous architecture constructed from a $\left.\{\mathrm{M} \text { (oxalate })_{4}\right\}^{4-}$ building unit. Chem. Commun. 2005, 993-995.

(15) Yeon, J.; Smith, M. D.; Sefat, A. S.; zur Loye, H.-C. Crystal Growth, Structural Characterization, and Magnetic Properties of New Uranium(IV) Containing Mixed Metal Oxalates: $\mathrm{Na}_{2} \mathrm{U}_{2} \mathrm{M}$ $\left(\mathrm{C}_{2} \mathrm{O}_{4}\right)_{6}\left(\mathrm{H}_{2} \mathrm{O}\right)_{4}\left(\mathrm{M}=\mathrm{Mn}^{2+}, \mathrm{Fe}^{2+}, \mathrm{Co}^{2+}\right.$, and $\left.\mathrm{Zn}^{2+}\right)$. Inorg. Chem. 2013, 52, 2199-2207.

(16) Wang, C.-M.; Liao, C.-H.; Chen, P.-L.; Lii, K.-H. $\mathrm{UF}_{3}\left(\mathrm{H}_{2} \mathrm{O}\right)-$ $\left(\mathrm{C}_{2} \mathrm{O}_{4}\right)_{0.5}$ : A Fluorooxalate of Tetravalent Uranium with a ThreeDimensional Framework Structure. Inorg. Chem. 2006, 45, 14361438.

(17) Mörtl, K. P.; Sutter, J.-P.; Golhen, S.; Ouahab, L.; Kahn, O. Structure and Magnetic Characteristics of an Oxalate-Bridged $\mathrm{U}(\mathrm{IV})-\mathrm{Mn}(\mathrm{II})$ Three-Dimensional Network. Inorg. Chem. 2000, 39, 1626-1627.

(18) Murase, R.; Leong, C. F.; D’Alessandro, D. M. Mixed Valency as a Strategy for Achieving Charge Delocalization in Semiconducting and Conducting Framework Materials. Inorg. Chem. 2017, 56, 14373-14382.

(19) Cladis, D. P.; Kiernicki, J. J.; Fanwick, P. E.; Bart, S. C. Multielectron reduction facilitated by a trianionic pyridine(diimine) ligand. Chem. Commun. 2013, 49, 4169-4171. 
(20) Kias, F.; Talbi, F.; Elkechai, A.; Boucekkine, A.; Hauchard, D.; Berthet, J.-C.; Ephritikhine, M. Redox Properties of Monocyclooctatetraenyl Uranium(IV) and (V) Complexes: Experimental and Relativistic DFT Studies. Organometallics 2017, 36, 3841-3853.

(21) Kitagawa, S.; Katawa, S. Coordination compounds of 1, 4dihydroxybenzoquinone and its homologues. Structures and properties. Coord. Chem. Rev. 2002, 224, 11-34.

(22) Guo, D.; McCusker, J. K. Spin Exchange Effects on the Physicochemical Properties of Tetraoxolene-Bridged Bimetallic Complexes. Inorg. Chem. 2007, 46, 3257-3274.

(23) Darago, L. E.; Aubrey, M. L.; Yu, C. J.; Gonzalez, M. I.; Long, J. R. Electronic Conductivity, Ferrimagnetic Ordering, and Reductive Insertion Mediated by Organic Mixed-Valence in a Ferric Semiquinoid Metal-Organic Framework. J. Am. Chem. Soc. 2015, 137, $15703-15711$.

(24) Jeon, I.-R.; Negru, B.; Van Duyne, R. P.; Harris, T. D. A 2D Semiquinone Radical-Containing Microporous Magnet with SolventInduced Switching from $T_{c}=26$ to $80 \mathrm{~K}$. J. Am. Chem. Soc. 2015, 137, 15699-15702.

(25) DeGayner, J. A.; Jeon, I.-R.; Sun, L.; Dincă, M.; Harris, T. D. $2 \mathrm{D}$ Conductive Iron-Quinoid Magnets Ordering up to $\mathrm{T}_{\mathrm{c}}=105 \mathrm{~K}$ via Heterogenous Redox Chemistry. J. Am. Chem. Soc. 2017, 139, 41754184.

(26) Murase, R.; Abrahams, B. F.; D’Alessandro, D. M.; Davies, C. G.; Hudson, T. A.; Jameson, G. N. L.; Moubaraki, B.; Murray, K. S.; Robson, R.; Sutton, A. L. Mixed Valency in a 3D Semiconducting Iron-Fluoranilate Coordination Polymer. Inorg. Chem. 2017, 56, 9025-9035.

(27) Sahadevan, S. A.; Abhervé, A.; Monni, N.; Sáenz de Pipaón, C.; Galán-Mascarós, J. R.; Waerenborgh, J. C.; Vieira, B. J. C.; AubanSenzier, P.; Pillet, S.; Bendeif, E.-E.; Alemany, P.; Canadell, E.; Mercuri, M. L.; Avarvari, N. Conducting Anilate-Based MixedValence $\mathrm{Fe}(\mathrm{II}) \mathrm{Fe}(\mathrm{III})$ Coordination Polymer: Small-Polaron Hopping Model for Oxalate-Type $\mathrm{Fe}(\mathrm{II}) \mathrm{Fe}(\mathrm{III}) 2 \mathrm{D}$ Networks. J. Am. Chem. Soc. 2018, 140, 12611-12621.

(28) Abrahams, B. F.; Coleiro, J.; Ha, K.; Hoskins, B. F.; Orchard, S. D.; Robson, R. Dihydroxybenzoquinone and chloranilic acid derivatives of rare earth metals. J. Chem. Soc., Dalton Trans. 2002, $1586-1594$.

(29) Zucchi, G.; Thuery, P.; Ephritikhine, M. CSD Private communication. Deposition-ID: CCDC 909452.

(30) Bram, A.; Bruederl, G.; Burzlaff, H.; Lange, J.; Rothammel, W.; Spengler, R.; Karayannis, M. I.; Veltsistas, P. G. Disodium bis(ochloranilato)uranyl(VI) hexahydrate. Acta Crystallogr., Sect. C: Cryst. Struct. Commun. 1994, 50, 178-180.

(31) Spengler, R.; Zimmermann, H.; Burzlaff, H.; Jansen, J.; Peschar, R.; Schenk, H. Ab initio structure determination from powder data using direct methods. Acta Crystallogr., Sect. B: Struct. Sci. 1994, 50, $578-582$.

(32) Here we compare the potentials of $\mathrm{Fe}^{3+}+\mathrm{e}^{-} \rightarrow \mathrm{Fe}^{2+}\left(E^{\circ}=\right.$ $+0.77 \mathrm{~V}$ vs NHE at $25{ }^{\circ} \mathrm{C}$, Housecroft, C. E.; Sharpe, A. G. Inorganic Chemistry, 5th ed.; Pearson Education Limited, 2018; Reduction and Oxidation, pp 255-282) with the two half-cell reactions $\mathrm{UO}_{2}{ }^{+}+\mathrm{e}^{-}$ $\rightarrow \mathrm{U}^{4+}$ and $\mathrm{UO}_{2}{ }^{2+}+2 \mathrm{e}^{-} \rightarrow \mathrm{U}^{4+}$, which have $E^{\circ}$ values in the range +0.38 to $+0.62 \mathrm{~V}$, and +0.27 to $+0.33 \mathrm{~V}$ (vs NHE at $25{ }^{\circ} \mathrm{C}$ ), respectively (Kihara, S.; Yoshida, Z.; Aoyagi, H.; Maeda, K.; Shirai, O.; Kitatsuji, Y.; Yoshida, Y. A critical evaluation of the redox properties of uranium, neptunium and plutonium ions in acidic aqueous solutions (Technical Report). Pure Appl. Chem. 1999, 71, 1771-1807.).

(33) Min, K. S.; DiPasquale, A. G.; Golen, J. A.; Rheingold, A. L.; Miller, J. S. Structure, and Magnetic Properties of Valence Ambiguous Dinuclear Antiferromagnetically Coupled Cobalt and Ferromagnetically Coupled Iron Complexes Containing the Chloranilate $(2-)$ and the Significantly Stronger Coupling Chloranilate(•3-) Radical Trianion. J. Am. Chem. Soc. 2007, 129, 2360-2368.

(34) Kindra, D. R.; Evans, W. J. Magnetic Susceptibility of Uranium Complexes. Chem. Rev. 2014, 114, 8865-8882.
(35) Hohloch, S.; Pankhurst, J. R.; Jaekel, E. E.; Parker, B. F.; Lussier, D. J.; Garner, M. E.; Booth, C. H.; Love, J. B.; Arnold, J. Benzoquinonoid-bridged dinuclear actinide complexes. Dalton Trans. 2017, 46, 11615-11625.

(36) Perez, F. M.; Gil, J. M.; Gil, F. J. M. Preparation, Infrared and Visible Spectra of Sulfate Complexes of Uranium(IV). Z. Anorg. Allg. Chem. 1980, 462, 231-240.

(37) Dolomanov, O. V.; Bourhis, L. J.; Gildea, R. J.; Howard, J. A. K.; Puschmann, H. OLEX2: a complete structure solution, refinement and analysis program. J. Appl. Crystallogr. 2009, 42, 339-341.

(38) Burla, M. C.; Caliandro, R.; Camalli, M.; Carrozzini, B.; Cascarano, G. L.; De Caro, L.; Giacovazzo, C.; Polidori, G.; Siliqi, D.; Spagna, R. IL MILIONE: a suite of computer programs for crystal structure solution of proteins. J. Appl. Crystallogr. 2007, 40, 609-613.

(39) Sheldrick, G. M. SHELXT - Integrated space-group and crystalstructure determination. Acta Crystallogr., Sect. A: Found. Adv. 2015, $71,3-8$. 